\title{
CAN EVOLUTIONARY PSYCHOLOGY EXPLAIN REPRODUCTIVE BEHAVIOR IN THE CONTEMPORARY UNITED STATES?
}

\author{
Satoshi Kanazawa \\ University of Canterbury
}

\begin{abstract}
Can evolutionary psychology explain human behavior in postindustrial societies? Critics point out that, contrary to its prediction, wealthy men in contemporary societies do not have more children than poor men. I replicate Pérusse's (1993) finding with a large, representative sample and demonstrate that, while they do not have more children, wealthy men nonetheless have more sex partners and copulate more frequently than poor men. They would therefore have achieved greater reproductive success in the ancestral environment without effective means of contraception.
\end{abstract}

Throughout human history, wealthy and powerful men of high status have had a greater number of mates and produced more children than poor and powerless men of low status (Betzig 1986). In ancient civilizations, kings, emperors, and sultans maintained large harems of hundreds and thousands of virgins, and local chiefs and noblemen kept several wives or concubines, while at the same time countless poor men in the countryside died mateless and childless (Betzig 1993). And these wealthy and powerful men of high status invariably left a large number of descendants. Moulay Ismail the Bloodthirsty, Emperor of Morocco from the late sixteenth to early seventeenth century, for instance, produced at least 1,042 offspring (Young 1994). (The exact number is not known because they stopped counting daughters after a while and eventually stopped counting sons after 700.) An emerging field of evolutionary psychology (Buss 1999) can explain why wealthy men have more mates and children than poor men, in terms of women's evolved desire to mate with such men because of their ability to make greater investment into the offspring.

In sharp contrast, a strong positive correlation between wealth and reproduction does not exist in contemporary society. Marriage and successful reproduction are no longer privileges of the wealthy and powerful, and men's reproductive success is not related to class. If anything, the correlation is negative; in contemporary industrial societies like the United States, poor families have more children than wealthy families. In the General Social Survey (GSS) from 1972-2000, for instance, the correlation between men's income (information on wealth is not available in the GSS) and the number of

Direct all correspondence to Satoshi Kanazawa, Department of Psychology, University of Canterbury, Private Bag 4800, Christchurch, New Zealand; e-mail: Satoshi.Kanazawa@canterbury.ac.nz

The Sociological Quarterly, Volume 44, Number 2, pages 291-302.

Copyright $\odot 2003$ by The Midwest Sociological Society.

All rights reserved. Send requests for permission to reprint to: Rights and Permissions, University of California Press, Journals Division, 2000 Center St., Ste. 303, Berkeley, CA 94704-1223.

ISSN: 0038-0253; online ISSN: 1533-8525 
children they have ever had, after controlling for age (which tends to increase both men's income and the number of children they have had) and current marital status, is weakly but significantly negative $(r=-.0195, p<.05, n=12,084)$. This is in clear contradiction to the prediction of evolutionary psychology.

Much more than an empirical correlation or its absence is at stake, however. Critics of evolutionary psychology point to this lack of strong positive correlation between wealth and reproductive success (predicted by evolutionary psychology) to question its applicability to contemporary society, calling it "the central theoretical problem of sociobiology" (Vining 1986). If evolutionary psychology cannot predict the reproductive behavior of men and women in modern, industrial societies, tens of thousands of years after they left the ancestral environment in which they evolved, then it undermines evolutionary psychology's claim to provide a general theoretical perspective for all social and behavioral sciences (Buss 1995).

In response to this challenge, Daniel Pérusse (1993) demonstrates that, while they don't necessarily have more children, unmarried wealthy men nonetheless have more mates and copulate more frequently than unmarried poor men. Thus, if it were not for the institution of monogamy and modern contraception, wealthy men even today would still have a larger number of children than poor men. Pérusse's conclusion, however, is based on a very small, snowball sample from one ethnic minority in Canada. In this article, I will replicate Pérusse's earlier finding with a large, high-quality, representative sample from the United States and demonstrate that wealthy men indeed do have more mates and copulate more frequently, while wealth does not have the same effect on women's mating activities. I will confirm the applicability and usefulness of evolutionary psychology for modern society, and therefore to social and behavioral sciences in general, by establishing that men's wealth still translates into their greater reproductive success had it not been for modern contraception, which men's brain, adapted to the ancestral environment, has difficulty comprehending.

\section{SOCIAL AND REPRODUCTIVE SUCCESS IN POSTINDUSTRIAL SOCIETY}

Evolution within a species operates via two distinct mechanisms: Natural selection and sexual selection. Natural selection is the process whereby some members of a species live longer than others (differential survival). Sexual selection is the process whereby males and females select each other for mating, and some individuals have greater reproductive success than others (differential reproductive success). ${ }^{1}$ While natural selection is often thought to be synonymous with evolution, sexual selection is probably a greater force than natural selection in shaping the genotypic natures and phenotypic behavior of humans and other animals (Miller 2000). From the evolutionary perspective, individuals need to survive in order to reproduce and take care of their offspring, to ensure their survival and reproduction.

How do men and women select each other for mating? There is by now extensive evidence that the criteria men and women use to select each other for mates are culturally universal and hence very likely part of universal human nature (Buss 1989). In every society, men prefer young and attractive women for mates, and women prefer wealthy and powerful men. This is because youth and physical attractiveness are indicators of health and fecundity, and wealth and power are indicators of resources available to 
invest in the offspring. In the environment of evolutionary adaptedness (EEA) or ancestral environment, to which human nature is adapted, women needed men's resources in order to ensure their offspring's survival and reproductive success. Women in every society therefore have evolved psychological mechanisms to prefer resourceful men as mates.

This is why wealthy men of high status throughout human history have managed to acquire a large number of mates, while poor men of low status were excluded from mating altogether. Men have competed fiercely to accumulate resources in order to attract mates, and those who have managed to accumulate great wealth have indeed acquired more mates and produced more children (Betzig 1986; Borgerhoff Mulder 1990). Wealth, power, and status have always been men's means toward the goal of reproductive success.

This pattern, however, seems to have broken down in contemporary society. In most industrial and postindustrial societies of the world, wealthy families have no more children than poor families. Daniel R. Vining (1986) points out that, in these societies, men fail to translate their "social success" (their wealth and status) into "reproductive success." He amasses a large amount of evidence to demonstrate, for instance, that there is a negative, rather than positive, relationship between class and the number of surviving children per couple in England and Wales and that prominent, wealthy men listed in Who's Who and Forbes 400 in Japan and the United States have no more children than the population average for their birth cohort. He argues that the absence of strong positive correlation between social and reproductive success predicted by evolutionary psychology represents "the central theoretical problem of human sociobiology" and calls into question the applicability of evolutionary psychology to contemporary societies. If women in every society have evolved psychological mechanisms to prefer to mate with wealthy and powerful men of high status, then why don't such men in modern industrial societies have greater reproductive success?

In response to this challenge, Pérusse (1993) argues that, while the ultimate goal of all biological organisms (including humans) is reproduction, the proximate mechanism with which evolution equips them to achieve this ultimate goal is the desire to copulate. In the ancestral environment, where humans evolved and to which human nature is adapted, there was no effective means of contraception. Thus men who copulated more frequently with more mates necessarily had a larger number of children (greater reproductive success) on average. In other words, ancestral men who behaved as though copulation, not reproduction, was the ultimate goal nonetheless attained the ultimate goal of reproductive success. In the ancestral environment, copulation and reproduction were essentially the same, and evolution didn't miss anything by equipping men with the proximate desire to copulate, instead of the ultimate desire to reproduce children.

More formally,

$$
\mathrm{NPC}=\sum_{i=1}^{n}\left(1-(1-p)^{\mathrm{P}_{i}}\right)
$$

where NPC is the number of potential conceptions for a man (in the absence of contraception), $n$ is the total number of female sex partners he has in a given time period, $p$ is the probability of conception per coital act (assumed to be the same for all coital acts for all women for simplicity), and $\mathrm{P}_{i}$ is the number of coital acts with partner $i$. It is easy to see that NPC (and thus reproductive success in the absence of contraception) is a monotonically increasing function of both $n$ and $\mathrm{P}_{i}$. The larger the number of female 
sex partners a man has in a given period, and the more coital acts he has with each of them, the more children he would have in the absence of contraception. However, NPC is a greater positive function of $n$ than of $\mathrm{P}_{i}$; because a woman cannot conceive again once she's pregnant, each additional coital act has a diminishing return to NPC, whereas there are no such diminishing returns to each additional female sex partner (Simpson 1993). ${ }^{2}$

Having established equation (1), Pérusse (1993) then conducts a small survey of francophone Caucasians in Quebec to investigate the relationship between cultural and reproductive success at both the ultimate and proximate levels. His data analyses show that, while social status is not at all related to the actual number of biological children men have had (the ultimate measure of reproductive success), controlling for age ( $r=$ $.00)$, social status is significantly correlated with NPC $(r=.16 ; p<.02)$. The correlation between status and NPC was particularly strong among unmarried men between 30 and $39(r=.63 ; p<.05)$. Pérusse's data therefore demonstrate that, had it not been for modern contraception, wealthy men of high status would still have a larger number of children even today in a postindustrial society like Quebec in the early 1990s.

While his distinction between reproductive success at the ultimate and proximate levels is quite ingenious, Pérusse's (1993) empirical analyses suffer from a large number of serious methodological problems (Bookstein 1993; Mueller 1993; Wahlsten 1993). First, he uses a snowball sample taken from acquaintances of students at two universities in Quebec and includes only second- or higher-generation native francophone, and Caucasian Quebecois. Second, his sample is very small. The total sample size $N=433$, and many analyses are based on smaller subgroups, sometimes as small as $N=8$ or 14 . Third, all of his conclusions are based on bivariate correlations computed for different age groups and marital statuses. Thus, potential spuriousness is a significant problem.

\section{EMPIRICAL ANALYSIS}

\section{Data}

I replicate Pérusse's (1993) earlier findings with data and methods that correct for all of his problems. I use seven consecutive waves $(1988,1989,1990,1991,1993,1994,1996)$ of the GSS, conducted by the National Opinion Research Center (NORC) at the University of Chicago. The NORC has administered the GSS either annually or biennially since 1973. Personal interviews are conducted with a nationally representative sample of noninstitutionalized adults in the United States. The sample size is about 1,500 for each annual survey and about 3,000 for each biennial survey. The total sample size for my analyses, pooled from the seven waves, is 13,409 (although each analysis uses a far smaller sample).

The nationally representative sample for each wave of the GSS solves Pérusse's (1993) first methodological problem of a snowball sample from one ethnic minority, while the large sample size solves his second problem. The multiple regression equations used below to predict men's and women's mating activities solve Pérusse's third problem of conclusions based on bivariate correlations within age categories.

\section{Control Variables}

In order to estimate the partial effect of income on the number of sexual partners and the frequency of sexual intercourse, I enter the following variables as controls. 
Age

Some of the dependent measures in the following analyses are cumulative (such as the lifetime number of sex partners), which is a monotonic function of age; it cannot decrease as respondents get older. At the same time, evolutionary psychological theory and research demonstrate that age has a positive effect on men's desirability as mates, because most human societies are gerontocratic and older men usually possess greater economic resources and occupy higher social statuses, while at the same time age has a negative effect on women's desirability as mates, because men value youth and fecundity in their mates (Buss 1989). In order to estimate the partial effect of income on reproductive behavior, it is therefore necessary to control for respondent's age.

\section{Race}

Past research shows that race has a significant effect on the onset and frequency of sexual activities and the number of sexual partners, where Africans have an earlier onset and greater frequency of sexual activities and a larger number of sexual partners than Europeans and Asians (Brewster 1994; Rowe and Rodgers 1994; Lynn 2000). I therefore control for the race of the respondent (1 if black; 0 if otherwise).

\section{Marital Status}

Current marital status of the respondent has two separate, countervailing effects. First, being married virtually guarantees one regular sexual partner at all time and thus has a positive effect on the frequency of sexual activities and the number of sexual partners. At the same time, however, being married makes it more difficult to have a large number of sexual partners and thus has a negative effect on the number of sexual partners. In order to eliminate this confound, I enter the respondent's current marital status as a control variable ( 1 if currently married; 0 if otherwise) in the multiple regression equations presented in Table 1.

\section{Religion}

Finally, past research shows that religion, like race, has a strong effect on sexual activities (Brewster et al. 1998; Charlotte et al. 2000). I therefore control for the respondent's religious affiliation with a series of four dummy variables (Catholic, Protestant, Jewish, and other, with "none" as the reference category).

\section{Wealthier Men Have More Lifetime Sex Partners and Have Sex More Frequently}

Table 1 presents the results of multiple regression equations, predicting the number of female sex partners men have had since age eighteen (left column) and the frequency of sex in the last twelve months (right column). Controlling for age, race, marital status, and religion, men's income has a significantly $(p<.05)$ positive effect on the number of 
TABLE 1. THE EFFECT OF MEN'S INCOME ON THE LIFETIME NUMBER OF SEX PARTNERS AND FREQUENCY OF SEX IN THE LAST TWELVE MONTHS

\begin{tabular}{lcc}
\hline & $\begin{array}{c}\text { Lifetime Number } \\
\text { of Sex Partners }\end{array}$ & $\begin{array}{c}\text { Frequency } \\
\text { of Sex }\end{array}$ \\
\hline Income & $.2797^{*}$ & $.0195^{* *}$ \\
Control variables & $(.1135)$ & $(.0059)$ \\
Age & $.3053^{* * * *}$ & $-.0396^{* * * *}$ \\
Race (black =1) & $(.0448)$ & $(.0023)$ \\
Marital status & $5.6238^{* *}$ & $.6721^{* * * *}$ \\
(Currently married $=1)$ & $(1.9625)$ & $.0990)$ \\
Religion & $-7.7853^{* * * *}$ & $1.0798^{* * * *}$ \\
Catholic & $(1.1519)$ & $(.0608)$ \\
Protestant & & \\
Jewish & $-4.0625^{*}$ & -.0597 \\
& $(1.7705)$ & $(.0939)$ \\
Other & $-5.5078^{* * *}$ & $-.2064^{*}$ \\
& $(1.6092)$ & $(.0857)$ \\
Constant & $10.8247^{* * *}$ & .1276 \\
& $(3.9302)$ & $(.2123)$ \\
$R^{2}$ & 4.3933 & .0670 \\
Number of cases & $(2.9947)$ & $(.1592)$ \\
\hline
\end{tabular}

Notes: Main entries are unstandardized coefficients; numbers in parentheses are standard errors; ${ }^{*} p<.05$; $* * p<.01 ; * * * p<.001 ; * * * * p<.0001$.

lifetime sex partners. Similarly, income has a significantly $(p<.01)$ positive effect on the frequency of sex in the last twelve months. In terms of equation (1) above, the results in Table 1 demonstrate that income increases both $n$ (the total number of sex partners) and $\mathrm{P}_{i}$ (the number of coital act per partner), thereby demonstrating that wealthy men would have greater NPC and more children had it not been for modern contraception.

Table 2 presents further evidence of greater NPC among wealthy men. It exhibits the results of multiple regression equations, predicting the number of sex partners currently unmarried men have had in the last five years (left column) and in the last twelve months (right column). Men's income has a significantly positive effect on both $(p<.01$ for five years, $p<.05$ for twelve months). Consistent with modern evolutionary psychology, currently unmarried women's income has no effect on the number of sex partners in the last five years or twelve months (Table 3). Wealth is a criterion that women use to select men as their mates, but not one that men use to select women as theirs (Buss 1989).

It is important to note that wealthy men, despite their economic means, are not more likely to have sex with prostitutes ( $p>.1$; results not shown). Wealthy men have more sex partners and have sex more frequently, not because they use their money to purchase sex, but because women choose them as their sex partners. 
TABLE 2. THE EFFECT OF MEN'S INCOME ON THE NUMBER OF SEX PARTNERS IN THE LAST FIVE YEARS AND IN THE LAST TWELVE MONTHS AMONG THE CURRENTLY UNMARRIED

\begin{tabular}{lcc}
\hline & Last Five Years & Last 12 Months \\
\hline Income & $.0353^{* *}$ & $.0147^{*}$ \\
& $(.0115)$ & $(.0075)$ \\
Control variables & & $-.0286^{* * * *}$ \\
Age & $-.0476^{* * * *}$ & $(.0031)$ \\
& $(.0049)$ & $.7188^{* * * *}$ \\
Race (black $=1)$ & $1.0284^{* * * *}$ & $(.1187)$ \\
& $(.1847)$ & -.1779 \\
Religion & & $(.1134)$ \\
Catholic & $-.3986^{*}$ & $-.3568^{* * *}$ \\
Protestant & $(.1752)$ & $(.1031)$ \\
Jewish & $-.5485^{* * *}$ & .1443 \\
& $(.1590)$ & $(.2890)$ \\
Other & .6968 & -.2649 \\
& $(.4386)$ & $(.2062)$ \\
Constant & -.5987 & 2.7149 \\
& $(.3205)$ & $(.1442)$ \\
$R^{2}$ & 4.7766 & .0780 \\
Number of cases & $(.2271)$ & 1,615 \\
\hline
\end{tabular}

Notes: Main entries are unstandardized coefficients; numbers in parentheses are standard errors; * $p<.05$; $* * p<.01 ; * * * p<.001 ; * * * * p<.0001$.

\section{Wealthy Men Are More Likely to Marry (But Wealthy Women Are Less Likely to Marry)}

Finally, Table 4 presents the results of logistic regression equations, predicting whether men (left column) or women (right column) have remained single. Income has a significantly $(p<.0001)$ negative effect on men's likelihood of remaining single. Controlling for age, race, and religion, wealthy men are far less likely to remain single and far more likely to get married than poor men, thereby securing at least one exclusive mate. In contrast, and once again consistent with the predictions of modern evolutionary psychology, women's income has a significantly $(p<.05)$ positive effect on the likelihood of remaining single. Controlling for age, race, and religion, wealthy women are less likely to marry than poor women.

Critics might note that my equations, while demonstrating the statistically significant effect of men's income on the number of sex partners and frequency of sex, nonetheless leave large proportions of variance unexplained. While the purpose of the current article is to demonstrate the significant effect of men's income on their sexual activities, I fully acknowledge that there are many other factors besides their income that account for men's desirability as sex partners. Probably the most important among these factors is the men's physical attractiveness. If there were an accurate measure of physical 
TABLE 3. THE EFFECT OF WOMEN'S INCOME ON THE NUMBER OF SEX

PARTNERS IN THE LAST FIVE YEARS AND IN THE LAST TWELVE MONTHS AMONG THE CURRENTLY UNMARRIED

\begin{tabular}{lcc}
\hline & Last Five Years & Last 12 Months \\
\hline Income & .0014 & .0011 \\
& $(.0081)$ & $(.0041)$ \\
Control variables & & \\
Age & $-.0551^{* * * *}$ & $-.0272^{* * * *}$ \\
Race (black $=1)$ & $.0031)$ & $. .0015)$ \\
& -.1128 & $.1234^{*}$ \\
Religion & $(.1042)$ & $(.0524)$ \\
Catholic & & $-.3178^{* * *}$ \\
Protestant & $\left(.5194^{* * *}\right.$ & $(.0787)$ \\
& $-.5628^{* * *}$ & $-.3184^{* * * *}$ \\
Jewish & $(.1391)$ & $(.0728)$ \\
Other & .1678 & -.2448 \\
& $(.3180)$ & $(.1542)$ \\
Constant & -.3356 & $\left(.4423^{* * *}\right.$ \\
& $(.2220)$ & 2.3503 \\
$R^{2}$ & 4.7096 & $(.0909)$ \\
Number of cases & $(.1780)$ & .1615 \\
\hline
\end{tabular}

Notes: Main entries are unstandardized coefficients; numbers in parentheses are standard errors; $* p<.05$; $* * p<.01 ; * * * p<.001 ; * * * * p<.0001$.

attractiveness in the GSS data, I would quite banally predict that it would have a significantly positive effect on men's number of sex partners, because women, even married women, seek out handsome men as casual sex partners because they carry good genes (Gangestad and Simpson 2000).

Another potential criticism is that the set of predictors in my equations accounts for greater variances in women's sexual activities than in men's. This is probably due to a very strong effect of age on women's number of sex partners $(\beta=-.4412$ for five years; $\beta=-.3772$ for twelve months). The negative effect of age on women's sex activities is much stronger than the positive effect of income on men's $(\beta=.0910$ for five years; $\beta=$ .0498 for twelve months). While the effect of age on sexual activities lies outside the purview of my current article, the strongly negative effect of age on women's number of sex partners is perfectly consistent with evolutionary psychology (Buss 1989). ${ }^{3}$

\section{DISCUSSION}

Empirical results presented in Tables 1-4 collectively replicate Pérusse's (1993) earlier findings from a small, snowball sample of Quebecois. While they do not necessarily have more children, wealthy men do indeed have more sex partners $(n)$ and have sex more frequently $\left(\mathrm{P}_{i}\right)$ than poor men, although income does not have the same effect on 
TABLE 4. THE EFFECT OF INCOME ON THE LIKELIHOOD OF HAVING NEVER BEEN MARRIED

\begin{tabular}{|c|c|c|}
\hline & Men & Women \\
\hline Income & $\begin{array}{c}-.0941 * * * * \\
(.0092)\end{array}$ & $\begin{array}{l}.0185^{*} \\
(.0087)\end{array}$ \\
\hline \multicolumn{3}{|l|}{ Control variables } \\
\hline Age & $\begin{array}{l}-.1077 * * * * \\
(.0050)\end{array}$ & $\begin{array}{c}-.1118 * * * * * \\
(.0051)\end{array}$ \\
\hline Race $($ black $=1)$ & $\begin{array}{l}.4489^{* * * * *} \\
(.1361)\end{array}$ & $\begin{array}{l}.9163^{* * * * *} \\
(.1136)\end{array}$ \\
\hline \multicolumn{3}{|l|}{ Religion } \\
\hline Catholic & $\begin{array}{c}-.3350^{*} \\
(.1306)\end{array}$ & $\begin{array}{c}-.2258 \\
(.1540)\end{array}$ \\
\hline Protestant & $\begin{array}{l}-.8006^{* * * * *} \\
(.1201)\end{array}$ & $\begin{array}{l}-.5937^{* * * * *} \\
(.1444)\end{array}$ \\
\hline Jewish & $\begin{array}{c}.3292 \\
(.3186)\end{array}$ & $\begin{array}{c}.4067 \\
(.3024)\end{array}$ \\
\hline Other & $\begin{array}{c}-.6583^{* *} \\
(.2267)\end{array}$ & $\begin{array}{c}.0011 \\
(.2412)\end{array}$ \\
\hline Constant & $\begin{array}{l}4.4688 \\
(.2048)\end{array}$ & $\begin{array}{l}2.7280 \\
(.2051)\end{array}$ \\
\hline-2 log likelihood & 3542.949 & 3613.708 \\
\hline$\chi^{2}(\mathrm{df}=7)$ & $1248.946^{* * * * *}$ & $864.873^{* * * *}$ \\
\hline$\%$ correctly classified & 82.09 & 82.49 \\
\hline Number of cases & 4,250 & 4,329 \\
\hline
\end{tabular}

Notes: Main entries are unstandardized coefficients; numbers in parentheses are standard errors; ${ }^{*} p<.05$; $* * p<.01 ; * * * p<.001 ; * * * * p<.0001$.

women's sexual behavior. Wealthy men are also far more likely to get married than poor men (even though the opposite is true among women). In the absence of modern contraception, wealthy men would therefore have more children, attaining greater reproductive success. However, the question inevitably arises: Why don't these wealthy men circumvent the contraception to attain reproductive success? Why do they have more sex with more partners without producing more children, when copulation without reproduction is meaningless from the evolutionary perspective?

Evolutionary psychology strongly rejects the view of the human brain as tabula rasa, and avers instead that it is content-rich and biased (Kanazawa 2001). The human brain, and all of its psychological mechanisms, are adapted to the EEA and are therefore biased in favor of viewing and responding to the world as if it were still the EEA. The psychological mechanisms that we possess today are still the same psychological mechanisms that we possessed in the EEA, because there has not been enough time since the end of the Pleistocene for the human brain (or any other body part, for that matter) to have adapted. It is not impossible to overcome the biases built into the human brain, but it is often difficult.

Our preference for sweets and fats illustrates my point (Barash 1982, pp. 144-147). Throughout most of human evolutionary history, procurement of sufficient calories to 
sustain the body physically was a particularly severe problem of adaptation (survival); malnutrition was a common problem. In this environment, those who had a "taste" for sweets and fats (which have higher calories) were better off physically than those who did not have the same taste. Those who had this taste therefore lived longer, led healthier lives, and produced higher-quality offspring than those who didn't. They in turn passed on their taste to their offspring, over many thousands of generations, until most of us living today have a strong preference for sweets and fats.

Today, however, we live in an environment where sweets and fats are abundantly available. In other words, the original adaptive problem no longer exists; very few people in industrial societies die of malnutrition. Yet we still possess the same psychological mechanism to compel us to consume sweets and fats, oblivious to the dramatic changes in the environment. Our evolved psychological mechanism (our preference for sweets and fats) compels us to behave as though we still live in the EEA, where malnutrition was a constant threat to survival. We consume a large quantity of sweets and fats as a result, even though the resultant obesity hinders both survival and successful reproduction.

Our response to mates and copulation is similar. In the EEA, where there was no effective means of contraception (other than abstinence), men's reproductive success was a direct function of the number of sex partners and frequency of sex with them, as equation (1) shows. The more partners they had, and the more frequently they had sex, the greater their reproductive success. Evolution therefore equipped men with the psychological mechanism to compel them to seek as many sex partners and copulate with them as frequently as possible. Any cognitive mechanism in men's brain that distinguishes women on the basis of whether they are on the pill or otherwise contracepting would have been utterly useless and biologically wasteful. Thus evolution never equipped men with such a cognitive mechanism, and contemporary men, who inherited their brain from their male ancestors, have difficulty distinguishing women or coital activities on the basis of whether there is contraception involved, just like they cannot tell whether starvation is likely in the near future. Of course, women still underwent menstrual cycles in the EEA, and some women were therefore more fertile at any given time than others, depending on where they were in their cycle. As a consequence, men do have cognitive, albeit unconscious, ability to evaluate women by where they are in their menstrual cycle and prefer those who are ovulating (Symons 1995; Grammer 1996; Buss 1999, pp. 145-147).

In the EEA, the number of female sex partners and the frequency of copulation with them were very accurate indicators of men's reproductive success. If the ancestral men behaved as though their ultimate goal was copulation, rather than reproduction, then they would have achieved reproductive success nonetheless. Men in contemporary society still act as if copulation was the ultimate, not proximate, goal, because they inherited the brain from their male ancestors who evolved in an environment where copulation and reproduction were essentially the same.

\section{ACKNOWLEDGMENTS}

I thank Monique Borgerhoff Mulder, Paula England, Alan S. Miller, Craig T. Palmer, and the $T S Q$ editor for their comments on earlier drafts. 


\section{NOTES}

1. This is how Darwin originally defined natural and sexual selection, as two separate processes. That's why he wrote two separate books-On the Origin of Species by Means of Natural Selection (1859), to explain natural selection, and The Descent of Man, and Selection in Relation to Sex (1871), to explain sexual selection. In the 1930s, however, biologists redefined natural selection to subsume sexual selection and began to contend that differential reproductive success was the currency of natural selection. This is now the orthodox in all biology textbooks.

I concur with Miller (2000, pp. 8-12), Campbell (2002, pp. 34-35), and others in the current generation of evolutionary psychologists and believe that we should return to Darwin's original definitions and treat natural and sexual selection as two distinct processes. I am fully aware that this view is still controversial and in the minority, but I firmly believe that the conceptual separation of natural and sexual selection will bring theoretical clarity to evolutionary biology and psychology. I thank Graham Macdonald and one anonymous $T S Q$ reviewer for pointing out that my definitions are unorthodox and Denis Dutton for convincing me that I am nonetheless right.

2. Holding the number of coital act $\mathrm{P}_{i}$ constant at 50 ("once a week") per partner, increasing the number of partners $n$ fourfold from 1 to 4 increases NPC exactly fourfold from .78 to 3.13 (400 percent increase). Holding the number of partners $n$ constant at 1 ("monogamy"), increasing the number of coital acts $\mathrm{P}_{1}$ fourfold from 50 ("once a week") to 200 ("four times a week") increase NPC only marginally from .78 to .998 (27.9 percent increase) (Simpson 1993, Table 1).

3. I thank the $T S Q$ Editor for these criticisms.

\section{REFERENCES}

Barash, David P. 1982. Sociobiology and Behavior. 2nd Ed. New York: Elsevier.

Betzig, Laura L. 1986. Despotism and Differential Reproduction: A Darwinian View of History. New York: Aldine de Gruyter.

1993. "Sex, Succession, and Stratification in the First Six Civilizations: How Powerful Men Reproduced, Passed Power on to Their Sons, and Used Power to Defend Their Wealth, Women, and Children.” Pp. 37-74 in Social Stratification and Socioeconomic Inequality, vol. 1: A Comparative Biosocial Analysis, edited by Lee Ellis. Westport, CT: Praeger.

Bookstein, Fred L. 1993. "Converting Cultural Success into Mating Failure by Aging." Behavioral and Brain Sciences 16:285-286.

Borgerhoff Mulder, Monique. 1990. "Kipsigis Women's Preferences for Wealthy Men: Evidence for Female Choice in Mammals?" Behavioral Ecology and Sociobiology 27:255-264.

Brewster, Karin L. 1994. "Race Differences in Sexual Activity among Adolescent Women: The Role of Neighborhood Characteristics." American Sociological Review 59:408-424.

Brewster, Karin L., Elizabeth C. Cooksey, David K. Guilkey, and Ronald R. Rindfuss. 1998. "The Changing Impact of Religion on the Sexual and Contraceptive Behavior of Adolescent Women in the United States." Journal of Marriage and the Family 60:493-504.

Buss, David M. 1989. "Sex Differences in Human Mate Preferences: Evolutionary Hypotheses Tested in 37 Cultures." Behavioral and Brain Sciences 12:1-49. . 1995. "Evolutionary Psychology: A New Paradigm for Psychological Science." Psychological Inquiry 6:1-30. 1999. Evolutionary Psychology: The New Science of the Mind. Boston: Allyn and Bacon.

Campbell, Anne. 2002. A Mind of Her Own: The Evolutionary Psychology of Women. Oxford: Oxford University Press.

Charlotte, Paul, Julie Fitzjohn, Jason Eberhart-Phillips, Peter Herbison, and Nigel Dickson. 2000. "Sexual Abstinence at Age 21 in New Zealand: The Importance of Religion." Social Science and Medicine 51:1-10.

Darwin, Charles. 1859. On the Origin of Species by Means of Natural Selection. London: John Murray. 
1871. The Descent of Man, and Selection in Relation to Sex. London: John Murray.

Gangestad, Steven W., and Jeffry A. Simpson. 2000. "The Evolution of Human Mating: Trade-Offs and Strategic Pluralism." Behavioral and Brain Sciences 23:573-644.

Grammer, Karl. 1996. "The Human Mating Game: The Battle of the Sexes and the War of Signals." Paper presented at the annual meetings of the Human Behavior and Evolution Society, Evanston, IL.

Kanazawa, Satoshi. 2001. "De Gustibus Est Disputandum.” Social Forces 79:1131-1163.

Lynn, Richard. 2000. "Race Differences in Sexual Behavior and Their Demographic Implications." Population and Environment 22:73-81.

Miller, Geoffrey F. 2000. The Mating Mind: How Sexual Choice Shaped the Evolution of the Human Mind. New York: Doubleday.

Mueller, Ulrich. 1993. "Actual and Potential Reproduction: There is No Substitute for Victory." Behavioral and Brain Sciences 16:301-303.

Pérusse, Daniel. 1993. "Cultural and Reproductive Success in Industrial Societies: Testing the Relationship at the Proximate and Ultimate Levels." Behavioral and Brain Sciences 16:267-322.

Rowe, David C., and Joseph L. Rodgers. 1994. "A Social Contagion Model of Adolescent Sexual Behavior: Explaining Race Differences." Social Biology 41:1-18.

Simpson, Jeffry A. 1993. "Male Reproductive Success as a Function of Social Status: Some Unanswered Evolutionary Questions." Behavioral and Brain Sciences 16:305-307.

Symons, Donald. 1995. "Beauty Is in the Adaptations of the Beholder: The Evolutionary Psychology of Human Female Sexual Attractiveness." Pp. 80-118 in Sexual Nature, Sexual Culture, edited by Paul R. Abramson and Steven D. Pinkerton. Chicago: University of Chicago Press.

Vining, Daniel R., Jr. 1986. "Social versus Reproductive Success: The Central Theoretical Problem of Human Sociobiology." Behavioral and Brain Sciences 9:167-216.

Wahlsten, Douglas. 1993. "Sociobiology Flops Again.” Behavioral and Brain Sciences 16:310-311.

Young, Mark C., ed. 1994. The Guinness Book of Records 1995. New York: Facts on Life. 